\title{
Phenomenology as a Resource for Patients
}

\author{
Dr Havi Carel \\ Department of History, Philosophy and Politics \\ UWE, Bristol \\ UK
}

\begin{abstract}
Patient support tools have drawn on a variety of disciplines, including psychotherapy, social psychology and social care. One discipline which has not so far been used to support patients is philosophy. This paper proposes that a particular philosophical approach, phenomenology, could prove useful for patients, giving them tools to reflect on and expand their understanding of their illness. I present a framework for a resource which could help patients to philosophically examine their illness, its impact on their life and its meaning. I explain the need for such a resource, provide philosophical grounding for it, and outline the epistemic and existential gains philosophy offers.

Illness often begins as an intrusion on one's life, but with time becomes a way of being. I argue that this transition impacts on core human features such as the experience of space and time, human abilities, and adaptability. It therefore requires philosophical analysis and response. The paper uses ideas from Husserl and Merleau-Ponty to present such a response, in the form of a phenomenological toolkit for patients. The toolkit includes viewing illness as a form of phenomenological reduction; thematising illness; and examining illness as changing the ill person's being in the world. I suggest that this toolkit could be offered to patients as a workshop, using phenomenological concepts, images and film clips to reflect on illness. I conclude by arguing that examining illness as a limit-case of embodied existence deepens our understanding of phenomenology.
\end{abstract}

Keywords: Phenomenology; Patient support; Patient experience; Lived experience; Illness; Phenomenological reduction; Thematisation; being in the world; Embodiment; Perception; MerleauPonty; Husserl; Heidegger.

\section{Introduction}

Receiving a diagnosis of a rare lung disease in April 2006 was the most influential event of my life. The significance of the event was disproportionate to the time it took. It was all over in twenty minutes. After being given a diagnosis of a serious, life-threatening disease I was sent home to try to piece together what suddenly became a shattered life. The end of that medical consultation was the beginning of an existential journey that undulated as my disease progressed. My medical care was good. But my overall feeling was one of extreme isolation and confusion. The medical and existential dimensions of my illness did not engage with one another. This seemed to me deeply wrong. In this paper I want to suggest that one way to bridge the gap between the medical and the existential meaning of illness is to provide patients with philosophical tools to think about their illness ${ }^{\text {ind }}$ and to enable them better to communicate their insights to the health professionals who care for them. 
In the first weeks after my diagnosis I used to wake up blissfully forgetful of my diagnosis. After a moment I would recall the horrible intruder that had lodged itself into my life. This odd phenomenon quickly disappeared. I am now continually aware of my illness, even if I am not explicitly thinking about it. With time, what initially seemed like a foreign invasion of a peaceful life became that life. Illness has become my way of being. In this paper I describe the process by which illness is initially an external intrusion, which is gradually embedded into one's being, becoming a "complete form of existence" (Merleau-Ponty 1962, p.107)." I claim that this transition is characterised by changes to core human features: the experience of space and time, our ability to perform tasks, and adapting to new circumstances. I examine these features and suggest that they mark the transition to illness as a complete form of life.

The structure of the paper is as follows. Section one asks what restricts patients' understanding of their illness. Section two presents embodiment, situation and motility as the basis for a thick account of illness. Section three introduces three themes - space and time, lost abilities, and adaptability and argues that these lie at the core of illness as a way of being. And section four outlines a phenomenological toolkit that can be offered to patients as a workshop.

\section{What restricts patients' understanding of illness?}

Many healthcare systems provide patient support in the form of social care, counselling and psychotherapy, in addition to medical services. iii However, the common medical view sees illness as physiological dysfunction. Within the context of a system aimed at treating disease, patients may be seen as overreacting if they give prominence to the changes illness has brought to their lives as a whole, rather than focusing on physical capacities such as mobility or energy levels. The materialism and mechanistic view of the body implicit in the medical model are of limited use when offered to patients as a framework for understanding their illness experience. This materialism is understandable given the subject matter of medicine. Physicians are competent at providing medical care for medical problems, not philosophical analysis or existential engagement. The consequence is that the experience of illness and changes it brings to patients' lives often remain unacknowledged within clinical medicine.

It is also important to appreciate the extent to which patients' own understanding of their illness is influenced by medical attitudes and their encounters with the healthcare system. Patients learn about their illness first and foremost from healthcare staff involved in their care. If this knowledge is largely based on medical facts, epidemiological evidence and the medical model, it may limit patients' existential understanding of their condition. Patients are often quick to mimic the medical discourse, which may lead to a sense of alienation and a lack of a first-person voice in patients' discourse about their illness. The reductive understanding of illness as disease (or 'disease plus') (Boorse 1977) may reduce a patient's ability to relate to her experiences as bound by the illness and as having an existential significance that is worthwhile exploring and that impacts on other aspects of life. ${ }^{\text {iv }}$

This emphasis on the medical view of illness also translates into a specific problem in qualitative healthcare data, which aims to capture the lived experience of illness. ${ }^{\vee}$ Patients' reports may be a 
response to researchers' questions and prompts, rather than a genuine attempt to construct an understanding of their unique existential position vis-à-vis the illness. As Paterson points out, participants may attempt to provide evidence to support the researchers' perspective, or may be unduly impacted by researchers' formulation of questions and general attitude (2003, p.991). Some argue that researchers' orientation towards the studied phenomenon seems to bias the answers patients provide as well as the researchers' analysis (Thorne and Paterson 1998; Thorne et al. 2002). In addition, interview questions are often standardised and focus on dysfunction, rather than on trying to understand the overall experience of illness in its diversity. As a result, some qualitative studies paint a bleak picture of the illness experience, which overemphasises the effects of illness (Barnett 2005; Arman \& Rehnsfeldt 2003; Charmaz 1983).

This bias may be an instance of the focusing illusion, described by Schkade and Kahneman (1998). The focusing illusion is the biasing effect that occurs when making a judgment about a broad category (e.g. wellbeing) while focusing on a particular feature of this category (e.g. winning the lottery or having a disability). The focusing illusion causes us to overemphasise the significance of that feature, thus overweighting it (ibid., p.340). A good example is a study of renal patients undergoing haemodialysis and healthy controls (Riis et al. 2005). Both the patients and the controls overestimated the impact of haemodialysis on wellbeing. In fact, both groups reported a similar level of wellbeing (ibid., p.6). It is possible that studies of illness experience suffer from the focusing illusion in study design and framing, as well as in patient responses to questions focusing on their illness.

Overall, there is no consensus on what the experience of illness is like, if it is like anything at all. Thorne and Paterson (1998) outline distinct phases of attitudes of researchers towards chronic illness: emphasising the negative aspects of illness (1980-1985); a more optimistic perspective (19901995); and concurrently, more emphasis on the expertise of chronically ill people regarding their illness and decision making. Morse emphasises the difficulties of capturing the experience of living with chronic illness given that the experience is in a constant state of flux (2000, p.539). Indeed, it may be that there is no coherent unified experience. However, it seems likely that there are particular themes of illness that can be uncovered by a phenomenological analysis (see below; cf. Toombs 1987, pp.228-235; Toombs 1988, pp.207-220).

Even in contexts where illness experience is discussed (e.g. support groups, online patient fora, 'pathographies') dominant and culturally specific approaches to illness provide a script for the ways illness 'should' be experienced. The ill person can feel further isolated and misunderstood if she does not recognise herself in those scripts. A recent example is Barbara Ehrenreich's Smile or Die, in which she describes the cultural imperative to be 'positive' about her breast cancer. ${ }^{\text {vi }}$ She writes: "The cheerfulness of breast cancer culture goes beyond mere absence of anger to what looks, all too often, like a positive embrace of the disease[...] Rather than providing emotional sustenance, the sugar-coating of cancer can exact a dreadful cost[...] it requires the denial of understandable feelings of anger and fear, all of which must be buried under a cosmetic layer of cheer[...] it takes effort to maintain the upbeat demeanour expected by others" (2009, p.27, p.41). Finally, the experience of illness is difficult to talk about, sad, and private. This introduces further obstacles to a frank discussion of this experience. These influences may restrict the understanding of illness. I suggest philosophy, and in particular phenomenology, as a means of mitigating some of these effects. 


\section{Phenomenology: a thick account of illness}

Phenomenology provides a set of concepts that are highly useful for a description of illness, without being prescriptive. As a descriptive method aimed at discerning acts of consciousness, phenomenology is uniquely suited to the exploration of the experience of illness. Phenomenology offers a step back from conventional understandings of illness and offers an opportunity for a genuinely unconstrained examination of illness. The reflective mode proposed here is not 'presuppositionless' in the radical Husserlian sense (Husserl 1970, p.72), of which Merleau-Ponty claimed: "The most important lesson which the reduction teaches us is the impossibility of a complete reduction" (1964, p.xiv). Rather, it is a distancing of oneself from habitual ways of understanding. ${ }^{\text {vii }}$ Illness imposes such a distancing from everyday routines and meanings, and contains opportunity for questioning and rediscovery that can be enriched by philosophy.

As a genuinely non-judgmental descriptive tool, a phenomenological approach to illness is able to overcome the problems outlined in section 1 , by avoiding making assumptions about what the experience of illness may be like for any individual. Phenomenology aims to re-achieve "a direct and primitive contact with the world", and is a "direct description of our experience as it is" (MerleauPonty 1964, p.vii). The phenomenological approach advocates distancing oneself from everyday given understanding. 'Distancing' in the phenomenological sense means leaving behind our general modes of interpretation and conventional meaning-generating practices in order to genuinely examine a given phenomenon. As Merleau-Ponty writes, "in order to see the world [...] we must break with our familiar acceptance of it" (1964, p.xiv). We thus bracket not only the conventional and social meanings of a phenomenon, but also the personal meanings one has been accustomed to attach to phenomena, in order to re-examine them.

Phenomenology can be used to order and describe the experiences of illness and provide a robust account of the embodied nature of illness employing its unique capacity to capture the 'lifestream', as Husserl called it (1999, p.20). It can also describe changes to agency, embodiment, interaction with environment, and other features of illness. Indeed, a philosophical framework that views cognition as embodied, focuses on subjective experience, and provides a robust existential account of selfhood, is well suited to understanding the experience of illness.

A phenomenological approach to illness asks how patients experience their disorder, rather than causal questions about the disorder or how to treat it. Its primary focus is on the first-person experience of those who are ill. This focus does not imply a view of people as solipsistic units. Phenomenology takes as its premise the intersubjective nature of our experience, which is structured by shared norms and ideas. On this view, the experience of any particular individual will be influenced by, and in constant dialogue with, others' experiences. But phenomenology is also able to capture idiosyncratic features of an individual's illness experience. Phenomenology understands consciousness as not only embodied but as socially and existentially situated. Its emphasis on intersubjectivity enables describing the experience of illness from multiple points of view. It can also be used to describe the experiences of a caregiver, a health care professional or a family member of an ill person. 
Phenomenology views illness as disruption of the body as lived, not as biological dysfunction (Toombs 1988; Carel 2010). At the basis of this understanding lies the view that physical possibility transforms subjectivity, so a change to one's embodiment will not merely be an external factor but a change in one's way of being. Physical ailments should not be understood as localised to a body function, but have to be considered within the general context of the ill person's life. Their impact and meaning also need to be understood within the specific situation of the patient. The same physical disease can be experienced and understood differently by two people in different situations. Similarly, the same physical disease can be understood differently by the same person in two different times.

Phenomenology understands experience as fundamentally embodied and lived in a particular environment. A flat terrain would provide a wheelchair user with an environment in which they may not be disabled. But an environment with stairs and slopes affords fewer opportunities and may be experienced as hostile. Phenomenology also emphasizes the meaningfulness of our experience. Human experience is not a string of sensations, nor is it the apprehension of shapes, colours and objects. The act of perception itself creates meaning and is a constituting act (Husserl 1999; MeleauPonty 1964). As an example, we can think of an English speaker and a non-English speaker hearing a sentence in English. Although they both hear the same string of sounds, the English speaker will experience that series of sounds as meaningful while the non-English speaker will not (Strawson 1994). Thus we can see that meaning is not contained in the sounds but in the perceptual acts.

The core philosophical contribution to understanding illness lies in phenomenology's account of human existence. Heidegger's fundamental characterisation of existence sees it as possibility. To be human (or Dasein), for Heidegger, is to exist as temporal openness and existential freedom. ${ }^{\text {vii }}$ The distinguishing feature of human existence is our ability to choose one possibility over another. This imbues the chosen possibility with significance and views human life as made up of enacted choices. These choices and their enactment take place in time, so Dasein's ultimate structure is that of finite temporality (Heidegger 1962, p.303).

Merleau-Ponty argues that possibility is not merely a temporal phenomenon, but rather is enacted. Being able to make a choice or pursue a goal relies on an ability to perform the relevant actions (Blattner 1996). When we change or limit one's embodiment, this has substantial impact on motility, comportment and spatiality. This affects one's ability to fulfil one's goals and act as a competent agent.

Iris Marion Young provides a detailed analysis of motility in her essay 'Throwing like a girl'. She writes: "The body's capacity and motion structure its surroundings and project meaningful possibilities and action, which in turn call the body's motion forth to enact them [...]" $(2005$, p.37). For Young, cultural, social, historical and educational factors can restrict modes of embodiment and create a subdued bodily style. The point, for Young, is not merely the restriction of physical movement but that motility is the foundation of subjectivity. Thus restricting movement is inhibiting certain ways of being in the world. The implication for illness is clear: restriction of bodily movement or abilities is a restriction of one's being in the world.

Merleau-Ponty sees motility as basic intentionality (1964, p.137). There can be no intentionality without bodily orientation in a world. "Consciousness is being-towards-the-thing through the 
intermediary of the body [...] to move one's body is to aim at things through it" (ibid., p.139). Motor intentionality is embedded within a broader concept: the intentional arc. The intentional arc is our general relationship to the world. This relationship includes motor intentionality but also a temporal structure, a human setting, and a moral and existential situation. Merleau-Ponty says: "It is this intentional arc which brings about the unity of the senses, of intelligence, of sensibility and motility. And it is this which 'goes limp' in illness" (ibid., p.136). The body is the core of our existence and the basis for any interaction with the world; it is our general medium for having a world (ibid., p.146). As Gallagher and Zahavi write, “...the body is considered a constitutive or transcendental principle, precisely because it is involved in the very possibility of experience" $(2008$, p. 135). So when something goes wrong with the body, as in illness, this affects human existence as a whole.

Viewed phenomenologically, illness is not an objective entity, but rather is experienced by patient and physician (Toombs 1987, p.221). Instead of seeing the illness experience as derived from an objective disease entity, on a phenomenological understanding illness appears to patient, physician, or other observer and does so differently to each (cf. Merleau-Ponty 1964, p.viii). This explains the difference in meaning and understanding that patients and physicians attribute to a given illness. It also explains how the same disease can give rise to different illness experiences in different people.

I suggest that as it becomes a form of life, illness affects a distancing from everyday habits, routines and practices, providing opportunity for philosophical reflection. This distancing happens in several ways. Illness imposes physical constraints which force the ill person to change their way of doing things, moving about, etc. Illness changes one's interaction with others. And illness may modify life plans, values, and understanding of time (Carel 2008). However, the existential and overarching nature of illness means that it cannot be compartmentalised into discrete areas. Instead I argue that these changes amount to a transformation of the ill person's being in the world as a whole. The next section examines three themes in this process: change to the experience of space and time; lost abilities; and adaptability.

\section{Themes of illness}

Although experiences of illness can be very different, phenomenologists have identified common features of illness. Toombs provides a list of eidetic (essential) characteristics of the experience of illness, including the perception of loss of wholeness, loss of certainty and control, loss of freedom to act, and loss of the familiar world (1987, p.229). Toombs claims that regardless of the peculiarities of any specific disease, any illness experience will display these features. These features include a profound sense of loss of bodily integrity; seeing the body as thwarting plans, impeding choices, and rendering actions impossible. She also sees illness as a disruption of a fundamental unity of body and self. There is a loss of faith in the body, or seeing it as a threat to self. The illness is perceived as a capricious interruption, bringing about a radical loss of certainty, loss of control, and a new understanding of the world as unpredictable. The ill person is isolated from her familiar world, as she is unable to carry on normal activities, and she experiences her future as truncated (ibid., pp.229234). In this section I suggest three additional themes of illness: changes to the experience of space and time, lost abilities, and adaptability. These are not exhaustive, and they overlap with Toombs' 
list. These themes specifically illuminate the transition of illness from being initially experienced as a foreign intrusion to being incorporated into one's being and becoming a 'complete form of life'.

Space and time: Illness causes disruption of the lived body, which interrupts the relationship between one's body and the environment. Concepts like 'far', 'difficult', and 'heavy' change their meaning for the individual, who may experience a further sense of alienation because her new use of concepts moves away from the norm. The new meaning also signals a move away from her former healthy self, which may cause a rift in her self-identity. The change is not merely linguistic; the ill person actually experiences the physical world as less welcoming, full of obstacles, difficult.

The experience of space is changed by illness. Distances increase, everyday routines take up more time, activities have to be forsaken or replaced by more suitable ones, and so on. Toombs, a philosopher suffering from MS, writes: "the bookcase outside my bedroom was once intended by my body as a 'repository for books'; then as 'that which is to be grasped for support on the way to the bathroom', and is now intended as 'an obstacle to get around with my wheelchair'." (1995, p.16) Toombs describes loss of mobility as "anchor[ing] one in the Here, engendering a heightened sense of distance between oneself and surrounding things." (ibid., p.11). In illness not only one's body, but one's sense of space is modified.

The experience of time is also modified by illness. Sustained pain or a poor prognosis may change one's experience of time (Toombs 1990). More time is given to each activity, which can cause the ill person to experience herself as 'useless' or as more disabled than she is (Toombs 1988). Lack of confidence about future health and ability may make one focus on the present (Carel 2008, Chapter 5). And memories of a healthy past become objects of regret, yearning, or a sense of discontinuity (Bury 1982). The experience of time may also change in response to a diagnosis, especially if accompanied by uncertain prognosis. Common themes include: rethinking one's priorities and commitments given a sense of limited time; an amplified sense of mortality and fragility; a reawakened appreciation of the good things in one's life, and privileging the present (Frank 2002). In illness priorities often change and it is an opportunity to consider how one has lived and how one would like to live (Lindsey 1996; Lindqvist et al 2006). The ill person may radically revise what she thinks of as optimal use of time.

A fundamental change to the way in which space and time are experienced may trigger philosophical exploration of these categories. For example, how plastic are they? What determines 'normal' experiences of space and time? Can there be continuity in identity and personhood given the radical change in one's experiences of these fundamental categories? In section 4 I discuss how this philosophical scrutiny could be offered to patients.

Lost abilities: Human physical abilities are self-evident and pervasive, and therefore normally elude consciousness (Kesserling 1990). Our self-understanding is based, in part, on participation in customary activities and operating within the realm of normal expectations for one's reference class. Dreyfus calls the body of tacit knowledge which underpins our sense of self, and interaction with the world and others, 'the background' (1995, p.4). Illness can suspend this background, giving rise to an experience of 'being not at home' (Svenaeus 2000, p.9). In practical terms, this breakdown implies a shift from a usually spontaneous 'I can', to an unfamiliar 'I cannot' (Kesserling 1990). This not only incapacitates the ill person but also removes her from the normal flux of life. This is not only due to 
physical inability but also because of social and psychological barriers to participation, for example, embarrassment or anxiety.

Heidegger describes breakdown as making transparent everyday understanding recede, giving rise to an experience of estrangement. He describes the breakdown of tools, which draws our attention away from the task at hand to the tool itself $(1962$, p.102). Tools may cease to function and become conspicuous, like the body does in the case of illness. The function of a pen that writes or a car that starts can be compared to the experience of health. Health is characterised by a transparency of the body, which is obedient and pain-free. In this situation, there is a normal feeling of being generally comfortable and in control of one's body. The breakdown of a tool draws attention to the tool as an object; it has turned from being a 'ready to hand' tool to a 'present at hand' object, whose uselessness is present through its conspicuousness (ibid., p.103). Although the body is not straightforwardly a tool, its dysfunction can give rise to a similar experience of conspicuousness. For example, in paraplegia one's limbs turn from being ready to hand useful entities to being present at hand, conspicuous objects. This experience takes on additional urgency in the case of the breakdown of the body, characterised by feelings of vulnerability, powerlessness and suffering; decline in energy and ability; and pain. The transition takes place in daily life, in which the transformation of the mundane everyday into an uncanny restrictive inability plays itself out in attempts to carry out simple routines (Kesserling 1990).

This transition is not permanent, but vacillating. Many patients talk about 'good days' and 'bad days', expressing the oscillation between the two modes. Paterson (2001) developed a 'shifting perspectives' model of illness, in which the illness moves from foreground to background, depending on context. As a result, the ill person may not be able to fix their attitude towards the illness, but may feel the need to have a clear stance towards it. This may lead to further frustration. An exploration of lost abilities can elucidate the change without characterising it as permanent.

Abilities lost through illness are now replaced by inability, as well as with newly formed adaptations (Kesserling 1990; Carel 2009). There is also a new emphasis on an 'I must!' that often accompanies illness. This dimension of illness reflects the new need to conform to a treatment regime and undergo painful or unpleasant procedures. Relations to self, others, and world are now reflected in vacillations between 'I can' and 'I cannot' or 'I must' (Kesserling 1990).

Changes in bodily capacities and in the body's ability to behave as expected often elicit dramatic repercussions in identity and evoke strong reactions from others (ibid.). The sense of failure, fragility and vulnerability arises from the experience of one's body as fractured by the illness. As a result, mobility and independence, self projection and self understanding, moods, emotions, and thoughts, are altered by illness. The global nature of the disruption is a fundamental feature of illness. Moreover illness exposes our vulnerability and dependence (Frank 2002). These losses become incorporated into a new way of being, in part through a process of adaptation.

Adaptability: The impairment of habitual patterns leads to a sense of loss of control and loss of mastery over one's body. But there are creative reactions to this loss. There is a process of adaptability, where the ill person discovers new ways to perform tasks, or experiences wellbeing within the context of the illness. Although it is a response to a diminished capacity, adaptability has a creative element. Finding a new way of performing an old task given an altered set of capacities is 
challenging; successful performance leads to a sense of achievement. I previously suggested that the process of adaptation to illness is not wholly negative (2009). Patients often report feelings of success when managing to negotiate an obstacle, peace with one's life, and joy about positive experiences in the present (Lindqvist et al 2006). This has been described as 'health within illness' (Lindsey 1996). This aspect of illness is often overlooked by the deficit-centred medical approach, and this leads patients to give little weight to the possible positive, if secondary, consequences of illness.

Adaptability in illness is a response to a change within one's body. The change is experienced immediately and unpredictably, leading to an experience of alienation from one's suddenly unfamiliar body. The introduction of tools to overcome bodily limitations creates a hybrid of body and tool. As Merleau-Ponty points out, external props can become an integral part of one's lived body. He writes: "the blind man's stick has ceased to be an object for him, and is no longer perceived for itself; its point has become an area of sensitivity, extending the scope and active radius of touch, and providing a parallel to sight" $(1962$, p.143).

In illness taken for granted assumptions and behaviours are disrupted and previous explanatory frameworks cease functioning (Williams 2003). The person who has become ill must find meaning for the new development, an explanation for her suffering and limitations. Williams notes mechanisms such as coping, normalisation, strategic mobilisation of resources, accommodation and denial (ibid.). Charmaz (1983) describes changes to one's sense of self and identity; and enduring, struggling and disruption are often used to describe the experience of illness (Ohman et al. 2003; Michael 1996). But there is also evidence of positive adaptive responses. Michael (1996) reports 'gaining control of an altered life direction' as a theme expressed by chronically ill people. Other adaptive themes include confronting loss, struggling for normalcy (Ohman et al. 2003), reformulating the self, transcending suffering and courage in the face of adversity. These adaptive themes demonstrate continued self exploration and creation of meaning against an adverse background. The capacity to understand the fragility and transience of life and nonetheless appreciate it is often reported by ill people. This insight is another creative dimension that can become explicit through the experience of illness.

\section{A phenomenology toolkit and workshop for patients}

Philosophical patient support does not take an already developed model of illness and present it to patients. Rather, its aim is to provide a flexible individual tool which patients can use to develop their understanding of their illness. I propose such a tool in the form of a toolkit for patients. The toolkit includes three phenomenological steps: the phenomenological reduction; thematising illness; and reviewing one's being in the world. In this section I sketch the toolkit and the workshop. ${ }^{\text {ix }}$

Illness is a limit-case or radical transformation that suspends everyday routines and conventional action and makes them explicit, much in the spirit of Merleau-Ponty's call to see the world anew (1964, p.viii). Serious illness removes our conventional understandings and expectations of our life, throwing everything into question at once. This is an opportunity to examine and re-evaluate choices, routines and habits. Eugen Fink defined the phenomenological reduction as wonder in the 
face of the world, a wonder that is suppressed by the natural attitude (Merleau-Ponty 1964, p.xiii). Merleau-Ponty says that illness "slackens the intentional threads which attach us to the world and thus brings them to our notice" (Ibid.). As soon as we withdraw from our fallen immersion in the everyday world, we can reflect on it philosophically. In illness such withdrawal becomes possible, or is even imposed. This can be an opportunity to philosophically re-examine one's being in the world.

Phenomenology is committed to making explicit aspects of experience that are overlooked by other approaches and may be poorly understood. An adequate approach to the experience of illness requires what Husserl calls the phenomenological reduction: a suspension of a 'natural attitude' of implicitly accepting the background sense of belonging to a world and various interpretive dogmas along with it. Bracketing the natural attitude is a withdrawal from the ordinarily implicit commitment to the reality of the world (Ratcliffe 2008, p.4). The bracketing turns the world into a phenomenon of being, instead of something that is. As Husserl says, this is not a sceptical or idealist position. Rather, this 'inhibiting' or 'putting out of play' of the natural attitude exposes "my pure living [...] the universe of phenomena in the phenomenological sense" (Husserl 1999, p.20). This suspension neither questions nor negates reality; rather, it allows under-theorised aspects of experience to become an object of inquiry, because it enables us to shift attention from the given object to the way in which it is given and its modes of appearance to us.

Bracketing the natural attitude towards illness suspends the belief in the reality of an objective disease entity. This suspension does not deny the objective reality of disease processes, but shifting the focus away from the disease entity and towards the experience of it can disclose new features of this experience. We usually take the disease entity for granted and posit it as the source of the illness experience. But in fact, for the ill person the illness experience comes before the objective disease entity (cf. Toombs 1987). Once the belief in the objective disease entity is bracketed and we are distanced from our usual way of experiencing, we can begin to explore how illness appears to the ill person, its structure, and its essential features. This is the first step in the phenomenological toolkit.

Illness forces a kind of phenomenological reduction on the ill person. What one ordinarily takes for granted becomes salient when it is lost or changed through illness. Illness involves a phenomenological reduction because it compels us to suspend "our normal, taken for granted way of approaching the world" (Moran 2000, p.144). This is particularly so in the case of mental illness, which involves changes to the natural attitude and therefore requires a methodological shift in order to understand it (Ratcliffe 2008, p.7). Using these phenomenological insights would help patients to engage in an unrestricted fashion with their illness. The phenomenological reduction can pave the way to exploring the unique significance illness has for a particular individual.

The second step in the toolkit is thematising illness. 'Thematising' refers to the act of attending to a phenomenon, which makes particular aspects of it explicit (Toombs 1987, p.222). A theme for a particular consciousness is that upon which it focuses its attention. But this does not simply denote the intentional object. It also takes into account the kind of attentional focus given to an entity. Thematising may include attending to the cognitive, emotive, moral, or aesthetic aspects of a phenomenon. A patient may thematise her illness as a central feature of her life, attending to her symptoms as pervasive, while the physician may thematise the illness as a 'case of cancer', attending 
to symptoms as diagnostic clues. The understanding that illness is not an objective entity and the exercise of thematising may help patients because it enables moving away from prescriptive pronouncements towards a descriptive mode.

Thematising can be used for bringing out the multiple perspectives on one's illness that patient, family, health professionals and others may have, as each will thematise an illness differently. The patient may thematise her illness emotively, while a health professional will thematise it cognitively. A family member may thematise illness as an experience of empathy. Thematising is useful for uncovering the variety of ways of appearing illness has. Exploring the different thematic centres illness may have can illuminate its multiple ways of appearing. By thematising different aspects of illness, as a social phenomenon, as a source of pain, as a trigger of innovation and so on, the multidimensionality of illness can be brought out. Thematising creates a complex, shifting, view of illness, as moving from foreground to background, as changing in meaning and as consisting of multiple perspectives. Also, the theme of one's particular concern is presented against a background, against the horizons in which it appears (Drummond 2007, p.201). Understanding the figure-background relationship helps to see illness as part of a broader context, and illness horizons that are more or less productive can be explored.

The third step of the toolkit is to take the new understanding of illness (as a form of distancing that has been thematised) and examine how it changes one's being in the world. The term 'being in the world' is used by Heidegger (1962) to denote the human being in the broadest sense. Being in the world includes the biological entity, the person, and her environment and meaningful connections. The main components of being in the world, for Heidegger, are being-in (inhabiting or dwelling in a place), the world (the meaningful network of entities, practices, and conventions which make up our world) and being, which is the open existence of humans, capable of temporal existence and understanding (Heidgger 1962).

This term provides a rich account of what it means to exist as a human being. The toolkit uses being in the world to capture the pervasive effects illness may have on one's sense of place, on one's interactions with the environment and with other people, on meanings and norms, and on the nexus of entities, habits, knowledge, and other people that makes up one's world. This term enables us to elaborate on the impact of illness richly and comprehensively. By moving away from a narrow understanding of illness as a biological process, a thick account of illness as a new way of being in the world can be developed by patients. Because illness turns from being an external intrusion to being a form of existence, the notion of being in the world is particularly appropriate. It helps understand the pervasive impact illness may have on all life domains, which are seen as interconnected.

One way in which such support can be delivered is as a one-day workshop for patients (this is currently being developed). ${ }^{x}$ It will use visual and sensual samples, as well as text and philosophical ideas, to trigger discussion and reflection. The evocative force of images and sounds will enable participants to explore possibly unnamed emotions and experiences. The phenomenological dimension of the workshop is amplified by this use of varied media, which will appeal to the experiential and perceptual, rather than restrict exploration to already formulated ideas. The workshop will aim to demonstrate that speaking about the experience of illness is not just a means 
for expressing already formed thoughts, but that speech brings thought into being by allowing it to form (Merleau-Ponty, 1962; Gallagher 2005). The workshop will also use non-linguistic means for self-description and self-reflection, for example, ask participants to create a collage of their situation, or choose a song that describes how they feel.

This workshop is planned as a full day so as to allow ample time for the development of ideas. It will begin by presenting the three steps of the toolkit, explained within the context of illness. Each step will be used to trigger discussion, combined with small group exercises. The three steps will then be used to analyse the experience of illness, using categories such as space and time, lost abilities, and adaptability. The exploration will then move on to use a variety of media: film clips, photographs, images, and music, which will be tailored to the specific context of the group. At the end of the workshop a reader of the main texts discussed in the workshop and a resource list will be distributed to participants. Each workshop would be unique, although with time a list of materials that were found useful will be collated.

The workshop will enable the expression of unique personal experiences, rather than pushing patients to adapt their experiences to medical or cultural expectations. The small-group structure of the workshop and the fact that participants all suffer from an illness provide a safe environment, which will allow participants to share the idiosyncrasies of their experiences, with no pressure for these to fit into a pre-given mould. Of its very nature the illness experiences of different patients will contain conflicting understandings. Such conflicting understandings do not need to be resolved because no single understanding is offered by phenomenology.

Further details are yet to be fleshed out. How could workshops be offered to patients? Would healthcare staff be able to take part in or observe the workshops? Would the workshops be run by patients, philosophers, or healthcare professionals? Will workshop material be recorded? These are open questions. Theoretical questions also remain open. For example, would there be a need to explicitly thematise the patient-patient relationship in the workshop?

Two issues remain to be developed in future work. First, can philosophy be accessible to a variety of patients? There is a risk that the workshop uptake will be small and self-selecting. There will be a need to make the philosophical material accessible to a range of potential participants. The second question is: can we utilise workshop data in order to inform interventions? These questions will be taken into account when piloting the workshop; hopefully mechanisms can be found to enable workshop themes to feed into decision making processes.

\section{Conclusion}

This paper proposed a concrete contribution phenomenology can make to understanding illness. I should like to close by making a few comments on the opposite movement, from illness to phenomenology. Illness can be seen as reframing the basic structures of perception, which are disturbed by changes to embodiment. Illness deepens our understanding of what it means to live as embodied, by illuminating normal patterns of motility, comportment and spatiality through their limit case. Merleau-Ponty uses this methodology when he examines pathological cases, such as 
phantom limb, anosognosia, and aphasia, to illuminate normalcy as full and spontaneous engagement with the world (1964). This methodology has been criticised as creating a false dichotomy between normalcy and pathology, and as conflating natural and normal function (Dorfman 2005). However, it is undeniable that illness raises philosophical questions about embodied existence, mind-body relationship, value and meaning of life, death and finitude, and human vulnerability. As a juncture of such central philosophical issues it deserves systematic philosophical exploration.

Illness is a pragmatic disruption of lived experience that forces reflection upon the ill person. It is not an academic, studied phenomenological reduction but a lived experience that motivates such a reduction. As such it is phenomenology in action. However, its contribution to phenomenology and to philosophy more generally has been overlooked. I hope that phenomenologists will continue to explore this important facet of human existence and its significance to the philosophical exploration of our lived experience.

\section{Acknowledgments}

I would like to thank Jeffrey Bishop, Eran Dorfman, Darian Meacham, Samir Okasha, Matthew Ratcliffe, Fredrik Svenaeus, Greg Tuck, Angela Woods and two anonymous referees for reading a draft of this paper and making helpful suggestions. I would also like to thank audiences at Durham University, University of Bristol, and The Concepts of Health and Illness Conference held at UWE, Bristol in September 2010, for their comments on this paper.

\section{References}

Arman M. \& A Rehnsfeldt (2003). The hidden suffering among breast cancer patients: a qualitative metasynthesis. Qualitative Health Research 13(4):510-527.

Barnett M. (2005). COPD: a phenomenological study of patients' experiences. Journal of Clinical Nursing 14, 805-812.

Blattner W. (1996). "Existence and self-understanding in Being and Time", Philosophy and Phenomenological Research 56(1):97-110.

Bury M. (1982). Chronic illness as biographical disruption. Sociology of Health and IIlness 4(2): 167182.

Boorse C. (1977). Health as a theoretical concept. Philosophy of Science 44(4):542-573.

Carel H. (2007). Can I be ill and happy? Philosophia 35:2, pp.95-110.

Carel H. (2008). Illness. Stockfield: Acumen.

Carel H. (2009). 'I am well, apart from the fact that I have cancer': explaining wellbeing within illness, in The Philosophy of Happiness, L. Bortolloti (ed.), Palgrave, Basinkstoke, 82-99. 
Carel H. (2010). Phenomenology and its application in medicine, Theoretical Medicine and Bioethics 32(1): 33-46.

Carel H. A Phenomenological Toolkit for Patients (in preparation).

Charmaz K. (1983). Loss of self: a fundamental form of suffering in the chronically ill. Sociology of Health and IIIness 5(2):168-195.

Dorfman E. (2004). Philosophy as an 'as'. In H. Carel \& D. Gamez (eds.), What Philosphy Is. London \& New York, Continuum Books, pp.168-177.

Dorfman E. (2005). Normality and pathology: towards a therapeutic phenomenology. Journal of the British Society for Phenomenology 36(1):23-38.

Dreyufs H. (1995). Being-in-the-world. A commentary on Heidegger's Being and Time, Division I. London \& Cambridge Mass.: MIT Press.

Drummond J. (2007). Historical Dictionary of Husserl's Philosophy. Lanham MD: Scarecrow Press.

Ehrenreich B. (2009). Smile or Die. London: Granta.

Frank A. (2002). At the Will of the Body. New York: Mariner Books.

Gallagher S. (2005). How the Body Shapes the Mind. Oxford: Oxford University Press.

Gallagher, S., and D. Zahavi. 2008. The phenomenological mind. New York: Routledge.

Heidegger M. (1962[1927]). Being and Time. Basil Blackwell, Oxford

Husserl E. (1970 [1954]). The Crisis of European Sciences and Transcendental Phenomenology. D. Carr (trans.), Northwestern University Press, Evanston III.

Husserl E. (1999 [1931]). Cartesian Meditations. D. Cairns (trans.), Dorcrecht: Kluwer.

Jennings D. (1986). The confusion between disease and illness in clinical medicine. Canadian Medical Association Journal 135:865-870.

Kesserling A. (1990). The experienced body, when taken-for-grantedness falters: a phenomenological study of living with breast cancer. PhD Dissertation available via UMI. (unpublished).

Lindqvist O., Widmark A. \& Rasmussen B. (2006). Reclaiming wellness - living with bodily problems as narrated by men with advanced prostate cancer. Cancer Nursing 29(4): 327-337.

Lindsey E. (1996). Health within illness: experiences of chronically ill/ disabled people. Journal of Advanced Nursing 24, 465-472.

Merleau-Ponty, M. 1964. The Primacy of Perception (trans. W. Cobb). Evanston, IL: Northwestern University Press.

Merleau-Ponty, M. 1962 [1945]. Phenomenology of perception. New York: Routledge. 
Michael S. R. (1996). Integrating Chronic Illness Into One's Life. Journal of Holistic Nursing 14(3):251267.

Moran D. (2000). Introduction to Phenomenology. Routledge: New York and London.

Morse J. (2000). Researching illness and injury: methodological considerations. Qualitative Health Research 10: 538-546.

Nordenfelt L. (1995). On the Nature of Health. Dordrecht: Reidel Publishing.

Ohman M., Söderberg S. \& Lundman B. (2003). Hovering between Suffering and Enduring: The Meaning of Living with Serious Chronic Illness. Qualitative Health Research 13(4):528-542.

Paterson B. (2001). The shifting perspectives model of chronic illness. Journal of Nursing Scholarship 33(1): 21-26.

Paterson B. (2003). The koala has claws: applications of the shifting perspectives model in research of chronic illness. Qualitative Health Research 13(7):987-994.

Ratcliffe M. (2008). Feelings of Being: Phenomenology, Psychiatry and the Sense of Reality. Oxford: Oxford University Press.

Riis J., J. Baron, G. Loewenstein \& C. Jepson (2005). Ignorance of hedonic adaptation to haemodialysis: a study using ecological momentary assessment. Journal of Experimental Psychology 134(1): 3-9.

Schkade D.A. and D. Kahneman (1998). Does living in California make people happy? a focusing illusion in judgments of life satisfaction. Psychological Science 9(5): 340-346.

Svenaeus F. (2009). The phenomenology of falling ill: an explication, critique and improvement of Sartre's theory of embodiment and alienation. Humane Studies 32:53-66.

Svenaeus F. (2000). Das Unheimliche - towards a phenomenology of illness. Medicine, Health Care and Philosophy 3, 3-16.

Strawson G. (1994). Mental Reality. Cambridge, Mass.: MIT Press.

Thorne S. \& Paterson B. (1998). Shifting images of chronic illness. Journal of Nursing Scholarship 30(2): 173-178.

Thorne S., B. Paterson, S. Acorn, C. Canam, G. Joachim \& C. Jillings (2002). Chronic illness experience: insights from a metastudy. Qualitative Health Research 12:4, 437-452.

Toombs S.K. (1987). The meaning of illness: a phenomenological approach to the patient-physician relationship. The Journal of Medicine and Philosophy 12, 219-240.

Toombs S.K. (1988). Illness and the paradigm of lived body. Theoretical medicine 9, 201-226.

Toombs S.K. (1990). The temporality of illness: four levels of experience. Theoretical Medicine 11, 227-241. 
Toombs S.K. (1995). The lived experience of disability. Human Studies 18, pp.9-23.

Williams S.J. (2003). Medicine and the Body. Sage Publications. London.

Young I.M. (2005). "Throwing like a girl”, in On Female Body Experience. Oxford: Oxford University Press, pp.27-45.

\footnotetext{
'Throughout the paper I will use the term 'illness' to denote the lived experience of an ill person, while 'disease' refers to a the physiological dysfunction giving rise to the illness. This use follows standard vocabulary in the literature (Svenaeus 2009; Jennings 1986) and allows a clear delineation of the set of experiences the article aims to explore.

ii I thank Jeff Bishop and an anonymous reviewer for bringing out the salience of this point.

iii In the UK, for example, cancer patients in some areas are offered counselling. Geriatric and paediatric health professionals work closely with social services.
}

${ }^{\text {iv }}$ Of course some patients in some contexts may choose to see their illness as a disease that is under their (or their physician's) control. For example, a transient injury such as a broken leg may be responded to in this way. Arthur Frank is critical of this view while recognising its desirability in some cases. This is a reflection of the fact that not all illnesses have an equally enduring and integrated impact on people's lives. That is why I chose to focus on severe and chronic illness in this paper. That is also the rationale for the choice of phenomenology as a descriptive method to be used in the workshop.

${ }^{v}$ I would like to note that this type of research is empirical, not philosophical, although sometimes inspired by phenomenological concepts and approaches.

${ }^{v i}$ Further evidence of the cultural specificity of understanding of illness can be found in the different titles of the book. While released as Smile or Die in the UK, the US title is Bright Sided, with a bright yellow cover and a 'smiley' to boot.

vii I thank Darian Meacham and Matthew Ratcliffe for raising this point.

viii Dasein is Heidegger's term for a human being, which can be literally translated as 'being there'.

${ }^{\text {ix }}$ For a full account of the toolkit see Carel (forthcoming 2012).

${ }^{x}$ The workshop will be piloted at the Bristol Oncology and Haematology Centre (in collaboration with Dr James Brennan) and at the Churchfield Surgery, Whitby (in collaboration with Dr Margaret Jackson and Peter Leviné). 